\title{
MOTIVOS QUE LEVAM AS GESTANTES A FAZEREM O PRÉ-NATAL: UM ESTUDO DAS REPRESENTAÇÕES SOCIAIS
}

\author{
REASONS THAT TAKE PREGNAT WOMEN TO MAKE PRENATAL: \\ A SOCIAL REPRESENTATION'S STUDY
}

\section{MOTIVOS QUE TIENEN LAS EMBARAZADAS PARA ATENDERSE DURANTE SU PRENATAL: UN ESTUDIO DE LAS REPRESENTACIONES SOCIALES}

\author{
Sebastião Junior Henrique Duarte ${ }^{*}$
}

\begin{abstract}
RESUMO
O pré-natal, há tempos, tem sido tema em discussão por seguimentos governamentais e sociais, na busca de melhorar os indicadores de saúde materno-infantil. Conhecer os motivos maternos que levam a realização do pré-natal é uma ferramenta fundamental propiciada pelo acolhimento, considerando as gestantes como protagonistas do processo. Nesse sentido as representações sociais contribuem para identificar o que permeia no modo de vida das gestantes. Tomando a importância da temática é que o estudo objetivou apreender as representações sociais das gestantes residentes no Jardim Marabá, município de Campo Grande/MS Brasil, a respeito dos motivos que levam a realização do pré-natal. Realizou-se uma pesquisa qualitativa da qual 12 gestantes proferiram tais motivos. Utilizou-se o discurso do sujeito coletivo para organização e análise das falas e a Teoria das Representações Sociais como referencial teórico. Os resultados evidenciaram que o acolhimento e o estabelecimento de vínculo com a equipe prénatalista, estão entre os motivos que levam a realização do prénatal, na opinião das gestantes que fazem o pré-natal na Unidade Básica de Saúde da Família Marabá, Campo Grande/MS Brasil.
\end{abstract}

Palavras chave: Atenção primária à saúde, cuidado pré-natal, saúde da família, pesquisa qualitativa.

\begin{abstract}
Prenatal care has always been a topic of discussion by the government and social sectors seeking indicators for improving maternal and child health. Knowing the reasons that lead to maternal performance of prenatal care is an essential tool, preferably promoted considering pregnant women as protagonists in the process. In this sense, social representations help identify how prenatal care pervades the lives of pregnant women. Considering the importance of this issue is that the study aimed to understand the social representations of pregnant women living in Garden Marabá city of Campo Grande / MS Brazil, regarding reasons leading prenatal care to be meet. We conducted a qualitative study in which 12 pregnant women expressed themselves about those reasons. We used the collective subject discourse to organize and analyze the discourses and Social Representation Theory as a theoretical framework. Results showed that the feeling welcomed and establishing a relationship with the pre-delivery team are some of the reasons leading to the achievement of prenatal care, according to pregnant women in prenatal care in the basic unit family health Marabá, Campo Grande / MS Brazil.
\end{abstract}

Key words: Primary health care, prenatal care, family health, qualitative research.

\footnotetext{
*Professor adjunto. Universidade Federal de Mato Grosso do Sul. E-mail: sjhd@usp.br
} 


\section{RESUMEN}

La atención prenatal siempre ha sido un tema en discusión por el gobierno y los sectores sociales, que buscan mejorar los indicadores de salud materna e infantil. Conocer las razones maternas que motivan el cumplimiento de este control es una herramienta fundamental, promovida preferentemente teniendo en cuenta a las mujeres embarazadas cómo protagonistas en el proceso. En este sentido, las representaciones sociales contribuyen a identificar como permea, la atención prenatal, la vida de las mujeres embarazadas. Considerando la importancia de la temática es que el estudio tuvo como objetivo comprender las representaciones sociales de las mujeres embarazadas que viven en Jardín Marabá, municipio de Campo Grande/ MS Brasil, respecto de los motivos que la llevan a cumplir la atención prenatal. Se realizó un estudio cualitativo en el que 12 mujeres embarazadas se expresaron respecto a esas razones. Se utilizó el discurso del sujeto colectivo para organizar y analizar los discursos y la Teoría de las Representaciones Sociales como referencial teórico. Los resultados mostraron que el sentirse acogidas y el establecimiento de una relación con el equipo de preparto son algunas de las razones que lleva a la consecución de la atención prenatal, en opinión de las mujeres embarazadas en control prenatal en el centro de salud familiar de Marabá, Campo Grande/MS Brasil.

Palabras clave: Atención primaria de salud, atención prenatal, salud de la familia, investigación cualitativa.

Fecha recepción: 14/10/11 Fecha aceptación: 14/08/12

\section{INTRODUÇÃO}

O pré-natal é um campo de intensa preocupação (1) tanto governamental quanto social. A assistência pré-natal tem merecido especial atenção na saúde materno-infantil, haja vista a persistência de índices desfavoráveis, tais como os coeficientes de mortalidade materna e infantil e tem motivado o surgimento de políticas voltadas ao ciclo gestacional e puerperal, como o Programa de Humanização no Pré-natal e Nascimento (PHPN).

O Programa de Humanização no Pré-natal e Nascimento tem o objetivo principal de assegurar a melhoria do acesso, da cobertura e da assistência ao parto e puerpério às gestantes e aos recém-nascidos. Entre as ações desse programa figuram a realização de exames laboratoriais básicos e os procedimentos obstétricos considerados essenciais, classificados como adequados, inadequados ou intermediários (2).

Contudo a assistência pré-natal não deve se restringir às ações clínico-obstétricas, mas incluir as ações de educação em saúde na rotina da assistência integral, assim como aspectos antropológicos, sociais e econômicos, que devem ser conhecidos pelos profissionais que assistem as mulheres grávidas, buscando entendê-las no contexto em que vivem, agem e reagem (3).

O pré-natal é um conjunto de ações voltadas à mulher grávida e ao bebê, visando a manutenção da saúde, onde são levados em consideração os aspectos bio-psicosócio-culturais das gestantes, seja através do diagnóstico de complicações evitáveis ou por meio da vigilância à saúde, estabelecida entre as gestantes e os profissionais envolvidos.

O enfermeiro deverá utilizar-se, além dos procedimentos técnicos, a comunicação com a gestante e seus familiares, promovendo vínculo de confiança e segurança, contribuindo para adesão das gestantes à atenção pré-natal (4).

Com a expansão do Programa Saúde da Família, a atenção ao pré-natal ocorre multidisciplinarmente, permitindo que as responsabilidades desse tipo de assistência sejam compartilhadas.

Sendo o pré-natal um momento importante na vida das mulheres e oferecido pelo sistema público de saúde, espera-se adesão da maioria das mulheres à esse acompanhamento. No entanto, os indicadores de saúde 
materno-infantil registram números preocupantes na mortalidade nesse grupo, colocando em dúvida se todas as grávidas fazem pré-natal.

Ressalta-se a necessidade de buscar nas gestantes os motivos que levam a sensibilização para a realização do acompanhamento pré-natal, de modo que sirva de parâmetros para equipes prénatalistas promover o acolhimento e planejar as ações do pré-natal. Muito importante conhecer a história obstétrica anterior, bem como o desfecho de uma gravidez prévia, no sentido de desvelar a assistência pré-natal, parto e puerpério. Entre os temores mais comuns na gravidez destacam-se o medo da morte tanto da gestante quanto do bebê, medo da dor, do esvaziamento e da castração, além da ansiedade que pode estar associada com uma vivência prévia negativa da experiência do pré-natal e parto (5).

$\mathrm{O}$ medo do parto pode ser considerado a expressão de vários sentimentos de ansiedade desenvolvidos durante o período gestacional e está associado ao aumento do risco de que a gestante tenha uma experiência de parto negativa, assim como de um novo pré-natal (6).

É fundamental os profissionais criarem um canal de diálogo com as gestantes, respeitando-se os valores culturais e as limitações que envolvem a gravidez, principalmente a gestante trabalhadora e que contribui para a manutenção financeira da família e divide o tempo entre o trabalho e a assistência à saúde. Este quadro configura uma nova necessidade em saúde por parte da população feminina.

Recomenda-se o estudo das Representações Sociais como elemento fundamental para o trabalho com a comunidade, principalmente com o grupo de gestantes, já que a gravidez é marcada por diversas crenças, fantasias e mitos que alimentam o senso comum. O conhecimento das Representações Sociais das gestantes pelos profissionais de saúde favorece ao desenvolvimento de habilidades que levam ao pré-natal qualificado.

Diante das fundamentações apresentadas esse estudo teve por objetivo apreender as representações sociais das gestantes residentes nas áreas de atuação das equipes do Programa Saúde da Família do Jardim Marabá, município de Campo Grande, Estado de Mato Grosso do Sul, a respeito dos motivos que levam a realização do pré-natal (7).

\section{METODOLOGIA}

O estudo teve abordagem qualitativa (8), foi composto por 12 mulheres grávidas, residentes nas áreas de atuação do Programa Saúde da Família do Jardim Marabá, município de Campo Grande MS Brasil, e que concordaram em participar da pesquisa.

Para a coleta dos dados, foi utilizada a técnica da entrevista individual, gravada, posteriormente transcrita e armazenada em CD ROM. As entrevistas ocorreram nas residências das gestantes. Foram incluídas as gestantes com idade acima dos 18 anos. Excluíram-se as gestantes adolescentes e as indígenas, dado o caráter peculiar da Resolução 196/96 para esses grupos de gestantes.

Foram adotados a Teoria das Representações Sociais (RS) como referencial teórico e o Discurso do Sujeito Coletivo (DSC) para organização e análise dos dados.

As RS são consideradas como uma forma de conhecimento socialmente elaborado e compartilhado com um objetivo prático e que contribui para a construção de uma realidade comum a um conjunto social $(9,10)$. Elas são equivalentes aos mitos e crenças das sociedades, ou seja, ao senso comum (11).

O DSC é uma técnica de construção do pensamento coletivo que visa revelar como as pessoas pensam, atribuem sentidos e manifestam posicionamentos sobre dado assunto. Trata-se de um compartilhamento de idéias dentro de um grupo social (12). Entende-se por discurso todo posicionamento argumentado. Para a construção do Discurso do Sujeito Coletivo 
foram utilizados trechos do discurso, ou seja, descrições literais dos depoimentos, reveladores da essência do conteúdo das representações e que são denominados de expressões-chave. A partir dos recortes de fala significativos foram identificadas as idéias centrais que constituem-se de palavras ou expressões linguísticas que revelam, de maneira precisa e sintética, o sentido presente nos depoimentos. Organizam-se, em mapas denominados de Instrumentos de Análise do Discurso (IAD), as expressões-chave e as idéias centrais. As expressões-chave exemplificadoras de idéias centrais semelhantes são organizadas de forma lógica e coerente, compondo um discurso único redigido na primeira pessoa do singular: o Discurso do Sujeito Coletivo (12).

No caso de surgirem depoimentos contraditórios a respeito de uma mesma questão são elaborados DSC para as falas concordantes e para as falas discordantes. No presente estudo, as falas não geraram conteúdos discordantes, razão pela qual ocorre a regularidade nos discursos.

O presente estudo foi submetido ao Comitê de Ética em Pesquisa Envolvendo Seres Humanos da Universidade Federal de Mato Grosso do Sul, obtendo parecer favorável expresso através do protocolo $\mathrm{n}^{\circ}$ 686. Para a realização dos procedimentos metodológicos as entrevistadas assinaram o termo de consentimento livre e esclarecido, conforme a Resolução 196/96 do Conselho Nacional de Saúde. As gestantes que participaram da pesquisa foram identificadas por números, visando preservar seu anonimato e o sigilo das informações.

\section{RESULTADOS}

Os resultados foram obtidos a partir de uma conversa informal com as gestantes, onde foi solicitado que cada uma delas dissesse tudo o que sabiam a respeito do pré-natal. Foram consideradas apenas as falas que apresentavam os motivos que levam a realização do pré-natal na perspectiva das gestantes, e destacou-se que se sentem acolhidas pelas duas equipes do Programa Saúde da Família que atuam na Unidade Básica de Saúde da Família do Jardim Marabá; tem suas necessidades atendidas e gostam do atendimento oferecido pelas equipes do PSF.

\section{Sente-se acolhida}

S1, S2, S3, S4, S5, S6, S7, S8 e S9

"Gosto do pré-natal aqui. Porque dão bastante atenção pra gente, tem lugar que não dá atenção... Acho que uma gestante tem que ser bem tratada, sou uma pessoa muito sensivel. Qualquer coisinha que você fala já choro, não sei por que, em todas as minhas gravidezes fico assim. Se meu marido fala alto já choro, sou muito sensivel... Gosto do posto, aqui do postinho, é tudo certinho. Você quer consultar não tem que esperar tanto tempo para marcar. $O$ (recepcionista) sempre ajuda a marcar rápido. O exame do dedo você vai e já faz pra ver as doenças, por isso gosto daqui. Gosto da médica que é muito boa, e porque aqui é um lugar perto da minha casa.

O pré-natal no Marabá é muito bom, a gente é bem atendida, a enfermeira conversa bastante com a gente e faz o acompanhamento do pré-natal, ela faz muito bem, confio nela (porque) no Marabá tem só clinico geral e atende todo mundo, não tem um específico só para gestante.

Recomendo o pré-natal aqui no Marabá. Antes eu pensava que as acadêmicas estavam aprendendo, mas perguntei: vocês estão aprendendo na gente? E elas explicaram. Só que é melhor elas. Dão mais atenção, explicam bem até a gente entender.

Gostei do posto aqui, por mais que no final da gravidez o médico não acompanhe, mas conheço todo mundo aqui, não tenho do que me queixar, me ajudam bastante, cada vez que venho aqui no posto sou bem tratada, graças à 
Deus... Se não fosse o posto eu não seria ninguém.

Até agora estou achando muito bom. Não sei se é porque estou no começo, mas desde o primeiro dia que fui, achei muito bom. A enfermeira é bem atenciosa. Todo mundo lá do posto. Os agentes também, que vem aqui em casa, ela conversa bastante, explica, então estou gostando... A médica falou que se eu passar mal ou sentir alguma coisa diferente do normal, posso ir ao posto procurar que serei bem atendida. As enfermeiras, os atendentes também (acadêmicos), as agentes de saúde falaram, você pode procurar que vai ser bem atendida... O postinho é muito bom, sempre estão atrás da gente. Mandam a agente de saúde para ver como estou. Sempre estão em contato comigo.

Escolhi (fazer o pré-natal com o médico do PSF) por que confio nele, gosto do atendimento (com a equipe do PSF), quando não posso consultar com o médico vou para a enfermeira. Se tiver alguma dúvida procuro a técnica de enfermagem, a agente comunitário de saúde e falo: olha estou precisando disso, estou precisando daquilo. Tem como dar uma olhada? É uma equipe trabalhando juntos, então são todos eles em um só grupo. Se estiver precisando de ajuda posso procurar. Um leva para o outro, se um não consegue o outro vai lá e tenta. Gosto da forma como eles trabalham, não tenho queixas. Pelo menos dali não tenho queixas. Gosto de tratar com a equipe deles. Sou daquelas assim, se não fui bem atendida você não serve pra mim. Acho que não tem que pegar e mal tratar. Um dia você pode estar no meu lugar. Atenda bem para ser bem atendido. Não faça para o outro o que não quer que façam para você. Então ali todos eles me atendem bem. Se um dia eles precisarem de alguma coisa que eu vou poder ajudar, vou ajudar, porque eles me ajudam".

\section{Tem suas necessidades atendidas}

S1, S2, S3, S4, S5, S6, S7, S8, S9 e S11

“Nem precisei marcar (consulta) porque já es- tava com a gravidez mais avançada. Cheguei lá e eles falaram: você vem tal dia. Passei pela enfermeira, depois foi com a doutora. Ela tentou escutar o coração do bebê, mas não conseguiu então ela pediu um ultrassom, inclusive ela desconfiava que o cordão umbilical estivesse enrolado no pescoço do bebê, mas graças à Deus está tudo bem comigo e com ele.

Das outras gravidezes não cheguei a fazer pré-natal (as duas primeiras) porque perdi de dois para três meses, mas do meu filho (de seis anos), do começo até o fim fiz aqui e estou fazendo dessa gravidez também. Tudo o que a gente precisa tem aqui.

Acho bom o pré-natal no Marabá, porque não precisa ir lá ao (Centro Regional de Saúde) que é muito longe da minha casa. Aqui é bem mais próximo, não tem nenhum problema para marcar consulta, não tem que ficar esperando. Atendem muito bem, eles tem muita paciência com a gente, são super bem com a gente. Atendem muito bem.

Todo mundo pergunta (porque eu faço prénatal no Marabá), porque o doutor lá não é ginecologista. Ele é médico da família. Então, quando falo que faço pré-natal com médico que não é ginecologista todo mundo critica, mas é o seguinte, chego no (Centro Regional de Saúde), tem ginecologistas lá, eu tinha muita cólica desde o início da gravidez e eu perguntava por que tenho cólica (e o ginecologista dizia) que é normal. Nunca vi gravidez com tanta cólica, ninguém explica nada. Consultei com o doutor (do PSF) e perguntei por que isso acontece e ele foi explicando. Tudo o que tenho dúvida ele explica. Lá no (Centro Regional de Saúde), o ginecologista só passa receita e te manda embora. Eles não explicam o que está acontecendo, então resolvi fazer com ele (médico do PSF), não me incomodo dele não ser ginecologista. O importante é esclarecer as dúvidas, não adianta nada consultar com um profissional que se diz ginecologista e ele não saber o que está fazendo ali, pra mim os ginecologistas de lá não sabem o que estão fazendo. Preferi (fazer) lá (no PSF), faço com ele. Se tenho dúvida ele esclarece, se acho que ele 
não esclareceu bem, venho e pesquiso e volto lá e falo: olha, descobri isso, isso e isso, e ele fala: é assim, assim e assado, então gosto da consulta com ele. É o que vou fazendo, mesmo não sendo um profissional da área. O ginecologista (do Centro Regional de Saúde) é da área, mas não atendeu do jeito que eu gostaria de ser atendida. Aquele dali é o médico da família, mas sabe? Não adianta você ser um profissional e não se entender com o paciente. Porque na minha opinião é isso, um ajudando o outro, ninguém sabe mais que ninguém. Um pode aprender com o outro. Você chega lá, eu sou um profissional, mas não explica nada? Então, ele não é médico da área (obstetra)? Mas não explica o que quero saber. O que consultei não gostei (obstetra) e dele (médico do PSF) gostei, então é por isso que eu comecei a fazer o prénatal com ele".

\section{Gosta do atendimento oferecido pela equi- pe do PSF}

S1, S2, S3, S4, S5, S6, S7, S8, S9, S10, S11 e S12

"Vim na recepção e falei que queria fazer o teste de gravidez. A enfermeira me consultou, perguntou o que eu tinha, mediu minha pressão e pediu o teste de gravidez. Ela falou pra mim voltar quando pegasse o resultado. Voltei e ela fez o cartão da gestante e a primeira consulta, mas quem acompanha meu pré-natal é a médica e os acadêmicos ajudantes dela, nem sempre são os mesmos... A enfermeira foi só da primeira vez quando eu vim fazer o teste, converso com ela, às vezes, e passo na médica. A agente comunitário de saúde e a dentista também me acompanham, só que já acabou o tratamento. Quanto as informações do pré-natal foram só com a médica.

A enfermeira pediu o teste de gravidez, marquei e na terça-feira fiz, quando peguei o resultado tinha dado positivo. Voltei e marquei uma consulta para a médica. A partir daí ela começou a pedir os exames mais detalhados e disse para agendar o retorno... Meu cartão de gestante foi a técnica de enfermagem que feze colheu o meu sangue para o teste do dedinho também. Passei pela dentista três meses e depois de sete meses ela pediu para passar novamente... A agente comunitário de saúde acompanha, indo em casa, fazendo as perguntas se vim ou não, vê minha carteirinha todo mês ou quando eu fico doente ela vai lá e faz as perguntas, marca tudo no caderno dela, é assim".

\section{DISCUSSÃO}

Nesses discursos observa-se que as gestantes estão satisfeitas com o atendimento no pré-natal. Entre os motivos para tal contentamento encontra-se a atenção desejada, o fato de serem bem tratadas, o conhecimento que têm com os membros que compõem as equipes e a satisfação com a forma do trabalho que é desenvolvido na unidade de saúde e nas visitas domiciliares, além da existência das facilidades geográficas. Isso faz com que se sintam importantes, valorizadas, vinculando-se tanto ao serviço quanto aos profissionais envolvidos.

O estabelecimento de vínculo entre as mulheres grávidas e a equipe pré-natalista foi apontado como importante quesito para a promoção da humanização da atenção e para a adesão e permanência das gestantes no serviço de atenção ao pré-natal (13). O DSC aponta a necessidade das gestantes em expressarem seus sentimentos, serem ouvidas e obterem respostas às suas inquietações. O DSC revela, ainda, que as mulheres grávidas são atendidas em suas necessidades e conseguem relacionar-se com os profissionais.

As gestantes que compuseram o discurso enfatizaram que há comunicação com a equipe pré-natalista, propiciado através da confiança e da garantia de atendimento quando dele necessitem. Considerando o pré-natal oferecido no Programa de Saúde da Família, destacam-se os princípios que norteiam a proposta do PSF (14). Entre eles está a habilidade em trabalhar com a comu- 
nidade, requerendo de cada integrante da equipe multiprofissional aprender a olhar as coisas pela ótica do usuário, perceber o que este sente e ser solidário com seus problemas, atitudes presentes no acolhimento. Observa-se nas falas das gestantes que o relacionamento entre elas e os membros das equipes de PSF é positivo, pois elas participam das decisões a respeito das condutas a adotar, recebem esclarecimento a suas dúvidas e, ao interrogarem, obtêm respostas, gostando do atendimento porque se sentem acolhidas.

A comunicação é apontada como elemento da relação terapêutica com a gestante (15). As autoras informam que a qualidade da interação entre os técnicos e as pessoas que são assistidas depende da disponibilidade do profissional em estabelecer relação de ajuda e acolhimento. Contudo, essa relação fica comprometida quando o profissional não está preparado para interagir com a clientela. O despreparo pode ser atribuído ao modo tradicional como é feita a formação dos profissionais de saúde, que valoriza os aspectos físicos em detrimento das características culturais e socioeconômicas.

Com relação a qualificação profissional o Ministério da Saúde implementou a Universidade Aberta do Sistema Único de Saúde (UNASUS), oferecendo curso de pós-graduação lato senso, ainda, o programa TESSAÚ$\mathrm{DE}$ que permite a opinião de especialistas em diversos assuntos, entres eles os relacionados ao pré-natal. Essas iniciativas contribuem para o estímulo a capacitação profissional e a decisão compartilhada, baseada em princípios científicos.

\section{CONSIDERAÇÕES FINAIS}

As entrevistadas deixam claro que, em termos de representações, a comunicação, o acolhimento e o vínculo foram os fatores mais valorizados e desejados por elas no pré-natal. Nesse sentido, as representações sociais funcionam como um sistema de interpretação da realidade que rege as relações dos indivíduos com seu meio físico e social, determinando suas atitudes e práticas (16). As representações sociais que as gestantes possuem orientam as ações e as práticas da realidade que apresentam, principalmente quando essas representações são positivas como apresentado por essas 12 mulheres grávidas.

Constata-se nesses discursos que a promoção do acolhimento praticado pelas equipes da Estratégia Saúde da Família do Jardim Marabá, Campo Grande/MS Brasil, mostrou-se como um modo de estabelecer vínculo positivo. $\mathrm{O}$ acolhimento visa inverter a lógica da organização e do funcionamento do serviço de saúde, priorizando as necessidades dos usuários (17).

Evidencia-se, no estudo, que as gestantes não só procuraram o serviço e receberam atendimento, como foram acompanhadas pelos profissionais das equipes da Estratégia Saúde da Família e desse modo receberam a atenção humanizada, constituindo-se em um dos motivos que levam a realização do pré-natal.

\section{REFERÊNCIAS}

1. Coutinho T, Teixeira MTB, Dain S, Sayd JD, Coutinho LM. Adequação do processo de assistência pré-natal entre usuárias do sistema único de saúde em Juiz de Fora MG. Rev Bras Ginecol Obstet. 2003; 25(10): 717-24.

2. Ministério da Saúde Brasil. Programa humanização do parto: humanização no pré-natal e nascimento. Brasília: Ministério da Saúde; 2002.

3. Duarte SJH, Andrede SMO. Assistência pré-natal no Programa Saúde da Família. Rev Enferm. 2006; 10 (1): 121-25.

4. Castro JC, Clapis MJ. Parto humanizado 
na percepção de enfermeiras obstétricas envolvidas com assistência ao parto. Rev Lat Am Enfermagem. 2005; 13 (6): 96067.

5. Piccinini CA, Gomes AG, Moreira LE, Lopes RS. Expectativas e sentimentos da gestante em relação ao seu bebê. Psic Teor e Pesq. 2004; 20 (3): 223-32.

6. Lopes RCS, Donelli TS, Lima CM, Piccinini CA. O antes e o depois: expectativas e experiências de mães sobre o parto. Psicol Reflex Crit. 2005; 18 (2): 247-54.

7. Duarte SJH. Representação social da gestante residente no Marabá a respeito do pré-natal, Campo Grande [Dissertação de mestrado]. [Campo Grande]: Saúde Coletiva. Universidade Federal de Mato Grosso do Sul; 2006.

8. Fontanella BJB, Ricas J, Turato ER. Amostragem por saturação em pesquisas qualitativas em saúde: contribuições teóricas. Cad Saude Publica. 2011; 27 (2): 388-94.

9. Moscovici S. Representações sociais: investigações em psicologia social. Petrópolis: Vozes; 2003.

10. González AE. Mujeres productoras y representaciones sociales. Movimiento de mujeres em lucha de Río Negro y Neu- quén. Pilquen. 2009; 11 (11): 1-12.

11. Jodelet D. Representações sociais: um domínio em expansão. Rio de Janeiro: Eduerj; 2002.

12. Lefèvre F, Lefèvre AMC. O discurso do sujeito coletivo: um novo enfoque em pesquisa qualitativa (desdobramentos). 2ed. Caxias do Sul: Educs; 2005.

13. Costa AM, Guilhem D, Walter MIMT. Atendimento a gestantes no sistema único de saúde. Rev Saude Publica. 2005; 39 (5): 768-74.

14. Wagner AL. Principles of family medicine. Toronto: Canadian College of Primary Physician; 1994.

15. Caron OAF, Silva IA. Parturiente e equipe obstétrica: a difícil arte da comunicação. Rev Lat Am Enfermagem. 2002; 10 (4): 485-92.

16. Abric JC. A abordagem estrutural das representações sociais. In: Moreira ASP, Oliveira DC., eds. Estudos interdisciplinares de representação social. 2ed. Goiânia: A.B. 2000: 27-38.

17. Gomes MCPA, Pinheiro R. Acolhimento e vínculo: práticas de integralidade na gestão do cuidado em saúde em grandes centros urbanos. Interface Comunic Saude Educ. 2005; 9(17): 287-301. 